\title{
PERSEPSI MAHASISWA DAN DOSEN PADA PEMBELAJARAN INTERPROFESSIONAL EDUCATION (IPE) DI PRODI D-III AKUPUNKTUR JURUSAN AKUPUNKTUR POLITEKNIK KESEHATAN KEMENKES SURAKARTA
}

\author{
Maria Dewi Christiyawati ${ }^{1}$, Saka Suminar ${ }^{2}$
}

\begin{abstract}
Background : IPE is an implementation of learning that is followed by two or more different professions to improve collaboration and quality of service which can be done in all learning, whether it is for undergraduate students or students of educataion clinic to create a professional health care personnel. The lack of IPE developer in Indonesia gives anew breakthrough for Health Polytechnic of Minister of Healt Surakarta to begin the initial steps introducing the IPE learning process to all students.

Methods : cross section with spreading the perception questionnaire about Interprofessional Education (modification of the IEPS) to students and faculty at D-III Acupuncture Study Program Acupuncture Health Polytechnic Department of Minister of Healths of Surakarta. Total sampling taken with the number of 53 respondents. Data were analyzed using Regressoni Logistik Biner.

Results show, it can be concluded that the student perceptions of instructional IPE in D-III status of Acupuncture, Acupuncture Health Polytechnic Department of Minister of Health of Surakarta who are 36 people $(92.31 \%)$ gave a good perception, and 3 people $(7,69 \%)$ gave a average perception.Perceptin lecture of D-III Acupuncture study program, Acupuncture Health Polytechnic Department of Minister of Health of Surakarta who are 12 people (85.7\%) gave a good perception and 2 people $(14,3 \%)$ gave average perception.
\end{abstract}

Keywords: Interprofessional Education (IPE), perception, students and lecturer

\section{PENDAHULUAN}

Transformasi sebuah pelayanan kesehatan yang berorientasikan kesembuhan pasien sudah lama diterapkan dalam peningkatan mutu, tetapi dalam pelaksanaanya masih banyak kasus penelantaran pasien dengan berbagai alasan yang justru terjadi karena kurangnya komunikasi antar tenaga kesehatan.

Fuadah (2014)menyatakan bahwa keterlambatan

keputusan, mengambil pelayanan kesehatan dan keterlambatan dalam melakukan tindakan di sarana pelayanan kesehatan dikatakan baik apabila tata kelola pelayanan dalam memberikan perawatan tidak terjadi tumpang tindih peran dan fungsi sebagai pemberi pelayanan dengan latar belakang profesi yang berbeda. Dampak dari kurangnya kerjasama antar tenaga kesehatan yang baik menjadikan pemanfaatan fasilitas pelayanan yang harus diterima masyarakat tidak efektif dan efisien.

Melalui kerjasama yang baik antar profesi kesehatan dalam pelayanan kesehatan, maka pasien akan ditangani secara holistik sehingga outcome perawatan dan kepuasan pasienakan meningkat. Melalui kerjasama yang baik dapat memfasilitasi adanya suatu solusi yang tepat dan mampu menyelesaikan permasalahan bagi pasien (Fuadah, 2014).WHO (1988) telah membuat sebuah grand design tentang pembetukan karakter kolaborasi dalam sebuah bentuk pendidikan formal yaitu berupa interprofessional education (IPE).IPE adalah suatu 
pelaksanaan pembelajaran yang diikuti oleh dua atau lebih profesi yang berbeda untuk meningkatkan kolaborasi dankualitaspelayanan dan pelakasanaanya dapat dilakukan dalam semua pembelajaran, baik itu tahap sarjana maupun tahap pendidikan klinik untuk menciptakan tenaga kesehatan yang profesional (Lee, 2009). Penerapan IPE pada masa akademik berhubungan dengan perubahan pengetahuan dan kesadaran mahasiswa mengenai peran dan tanggung jawab, memahami kerjasama tim dan kolaborasi dengan profesi kesehatan lain (Finch, 2000). Dengan adanya pendidikan yang terintegrasi, mahasiswa mampu memahami bagaimana bekerja secara interprofesi, sehingga menumbuhkan kesiapan mahasiswa untuk ditempatkan sebagai anggota tim kolaboratif (WHO, 2010). Kompetensi dalam IPE salah satunya adalah kerjasama (teamwork) dimana kemampuan bekerja sama (teamwork skill) menjadi komponen yang penting dalam keefektifan pelaksanaan kolaborasi interprofesi dalam memberikan pelayanan. Kesiapan untuk kerjasama interprofesi merupakan salah satu pencapaian dari pendidikan interprofessional (Fuadah, 2014).Pengembang IPE yang dirasa masih sangat kurang di Indonesia memberikan terobosan baru bagi Politeknik Kesehatan Kemenkes Surakarta untuk memulai langkah awal mengenalkan pembelajaran IPE kepada seluruh mahasiswa. Politeknik Kesehatan Kemenkes Surakarta memiliki 8 jurusan besar diantaranya Perawat, Bidan, Fisioterapi, Okupasi Terapi, Terapi Wicara, Orthotik Prosthetik, Akupunktur, dan Jamu. Berdasarkan hal tersebut Politeknik Kesehatan Surakarta dirasa sudah memenuhi persyaratan untuk menerapkan sistem pembelajaran IPE yang terdiri dua atau lebih profesi kesehatan kepada seluruh mahasiswa yang terdiri dari 8 jurusan besar tersebut. Dari 8 jurusan di Politeknik Kesehatan Surakarta jurusan Akupunktur yang pertama kali menerapkan sistem pembelajaran IPE kepada mahasiswanya. Pembelajaran IPE dimulai sejak tahun pembelajaran 2016/2017 yang diterapkan kepada mahasiswa tingkat III prodi D-III Akupunktur dan tingkat IV Prodi DIV Akupunktur Jurusan Akupunktur Politeknik Kesehatan Kemenkes Surakarta.

\section{TUJUAN PENELITIAN}

Penelitian ditujukan untuk mengetahui persepsi mahasiswa dan dosen dalam pembelajaran IPE di Prodi D-III Akupunktur Jurusan Akupunktur Politeknik Kesehatan Kemenkes Surakarta.

\section{METODE PENELITIAN}

Desain penelitian ini adalah dengan menyebarkan kuesioner persepsi tentang pendidikan Interprofessional (modifikasi dari IEPS) kepada mahasiswa dan dosen di Prodi D-III Akupunktur Jurusan Akupunktur Politeknik Kesehatan Kemenkes Surakarta.

Sampel diambil secara total sampling dengan jumlah 53 responden. Data dianalisa dengan Uji Regresi Logistik Biner Bivariat dan Uji Regresi Logistik Biner Multivariat.

\section{HASIL PENELITIAN}

1. Analisis Univariat

Karakteristik responden memuat data tentang latar belakang responden yang terdiri dari usia, jenis kelamin, dan pendidikan terakhir. 
Tabel 1.

Distribusi Frekuensi Mahasiswa

Prodi D-III Akupunktur Jurusan

Akupunktur Politeknik Kesehatan

Kemenkes Surakarta

Berdasarkan Usia

\begin{tabular}{lcc}
\hline Usia & $f$ & $\%$ \\
\hline 20 & 1 & 2.6 \\
21 & 21 & 53.8 \\
22 & 15 & 38.5 \\
23 & 1 & 2.6 \\
24 & 1 & 2.6 \\
\hline Jumlah & 39 & 100 \\
\hline \multicolumn{4}{c}{} \\
Usia responden penelitian \\
sebanyak 39 orang terdiri dari \\
usia minimum 20 tahun dan usia \\
maksimum 24 tahun. Usia \\
responden penelitian terbanyak \\
21 tahun & sebnyak 20 orang \\
(53.8\%). &
\end{tabular}

Tabel 2.

Distribusi Frekuensi Dosen

Akupunktur Jurusan Akupunktur

Politeknik Kesehatan Kemenkes

Surakarta Berdasarkan Usia

\begin{tabular}{ccc}
\hline Usia & $f$ & $\%$ \\
\hline 27 & 5 & 35.7 \\
30 & 1 & 7.1 \\
34 & 1 & 7.1 \\
40 & 1 & 7.1 \\
43 & 1 & 7.1 \\
44 & 1 & 7.1 \\
46 & 1 & 7.1 \\
47 & 1 & 7.1 \\
56 & 1 & 7.1 \\
60 & 1 & 7.1 \\
\hline Jumlah & 14 & 100 \\
\hline
\end{tabular}

Usia responden penelitian sebanyak 14 orang terdiri dari usia minimum 27 tahun dan usia maksimum 60 tahun. Usia responden penelitian terbanyak 27 tahun sebnyak 5 orang (35.7\%).
Tabel 3.

Distribusi Frekuensi Dosen

Akupunktur Jurusan Akupunktur

Politeknik Kesehatan Kemenkes Surakarta Berdasarkan

Pendidikan

\begin{tabular}{ccc}
\hline Pendidikan & $\mathrm{f}$ & $\%$ \\
\hline S 1 & 4 & 28.6 \\
S 2 & 9 & 64.3 \\
S 3 & 1 & 7.1 \\
\hline Jumlah & 14 & 100 \\
\hline
\end{tabular}

Data responden berdasarkan pendidikan didominasi oleh S2 sebanyak 9 orang (64.3\%), S1 sebanyak 4 orang (28.6\%) dan sisanya S3 sebnayak 1 orang $(7.1 \%)$.

2. Analisis Bivariat

Tabel 4.

Persepsi Mahasiswa Prodi D-III Akupunktur Jurusan Akupunktur Politeknik Kesehatan Kemenkes Surakarta

\begin{tabular}{lcc}
\hline Kategori & $f$ & $\%$ \\
\hline Baik & 36 & 92.31 \\
Sedang & 3 & 7.69 \\
Buruk & 0 & 0 \\
\hline Jumlah & 39 & 100 \\
\hline
\end{tabular}

Data responden berdasarkan persepsi mahasiswa prodi D-III akupunktur jurusan akupunktur sebanyak 36 orang (92.31\%) responden Persepsi mahasiswa Prodi D-III Akupunktur Jurusan Akupunktur Politeknik KesehatanKemenkes Surakarta memberikan hasil persepsi baik terhadap pembelajaran IPE, dan sisanya sebnayak 3 orang $(7.69 \%)$ memberikan hasil persepsi sedang terhadap pembelajaran IPE. 
Tabel 5.

Persepsi Dosen Akupunktur Jurusan Akupunktur Politeknik Kesehatan Kemenkes Surakarta

\begin{tabular}{ccc}
\hline Kategori & $\mathrm{F}$ & $\%$ \\
\hline Baik & 12 & 85.7 \\
Sedang & 2 & 14.3 \\
Buruk & 0 & 0 \\
\hline Jumlah & 14 & 100 \\
\hline
\end{tabular}

Data responden berdasarkan persepsi dosen jurusan akupunktur sebanyak 12 orang $(85.7 \%)$ responden memberikan hasil persepsi baik terhadap pembelajaran IPE, dan sisanya sebnayak 2 orang (14.3\%) memberikan hasil persepsi sedang terhadap pembelajaran IPE.

\section{PEMBAHASAN}

Setelah dilakukan analisis terhadap jawaban responden berdasarkan kuesioner yang telah disebarkan, berdasarkan tabel 4 dan 5 didapatkan hasil bahwa mahasiswa jurusan akupunktur memberikan persepsi yang baik terhadap pembelajaran IPE di Prodi D-III Akupunktur sebanyak 36 orang $(92.31 \%)$ dan sebanyak 3 orang $(7.69 \%)$ memberikan persepsi sedang terhadap pembelajaran IPE di Prodi D-III Akupunktur, sedangkan untuk dosen jurusan akupunktur sebanyak 12 orang (85.7\%) memberikan persepsi yang baik terhadap pembelajaran IPE di Prodi D-III Akupunktur dan 2 orang (14.3\%) memberikan persepsi sedang terhadap pembelajaran IPE di Prodi D-III Akupunktur. Berdasarkan penelitian yang pernah dilakukan oleh Fauziyah (2010) melakukan penelitian yang berjudul analisi gambaran persepsi dan kesiapan mahasiswa profesi Fakultas Kedokteran UGM terhadap Interprofessional Education di tatanan klinik. Penelitian dilakukan terhadap $133 \quad$ mahasiswa pendidikan dokter dan ilmu keperawatan tahap pendidikan profesi. Diperoleh hasil sebanyak 117 (87.97\%) mahasiswa memiliki persepsi baik terhadap IPE dan 11 (83.45\%) mahasiswa menunjukkan kesiapan yang baik terhadap IPE. Penelitian serupa dilakukan Ulung (2014) yang berjudul persepsi mahasiswa Fakultas Kedokteran dan IImu Kesehatan UIN Syarif Hidayatullah Jakarta terhadap Interprofessional Education. Penelitian dilakukan terhadap 143 mahasiswa FKIK UIN Syarif Hidayatullah Jakarta mempunyai persepsi terhadap IPE dalam kategori baik (97.21\%).

Salah satu faktor yang memungkinkan terjadinya perbedaan persepsi antar responden yaitu adanya perbedaan daya tangkap selama proses pembelajaran IPE berlangsung. Menurut sarwono (1996) salah satu faktor yang dapat mempengaruhi perbedaan persepsi yaitu adanya sebuah perhatian, biasanya seseorang tidak menangkap seluruh rangsangan yang ada disekitar sekaligus, tetapi memfokuskan perhatian pada satu atau dua obyek saja. Perbedaan fokus antara satu orang dengan orang lain menyebabkan perbedaan persepsi.

Kurangnya perhatian mahasiswa selama proses pembelajaran IPE berlangsung dapat mengakibatkn kurangnya informasi yang didapatkn mengenai IPE, sehingga dalam penilaian persepsi mereka memberikan hasil yang tidak maksimal. Pentingnya pengetahuan IPE bagi mahasiswa kesehatan bertujuan untuk melatih mahasiswa lebih mengenal peran profesi kesehatan yang lain, sehingga diharapkan mahasiswa mampu berkolaborasi dengan tenaga kesehatan lainnya dalam pemberian pelayanan kesehatan (Mariyono 
dan Claramita, 2014). Mahasiswa dinilai memiliki tingkat intelektualitas yang tinggi, kecerdasan dalam berpikir dan perencanaan dalam bertindak. Berpikir kritis dan bertindak dengan cepat dan tepat merupakan sifat yang cenderung melekat pada diri setiap mahasiswa, yang merupakan prinsip saling melengkapi. Pembelajaran IPE pada mahasiswa merupakan bentuk kajian awal yang penting dan paling sering dilakukan di beberapa negara yang telah menerapkan dan mulai mengembangkan IPE karena mahasiswa merupakan pemangku kepentingan utama dalam upaya pengembangan dan penerapan IPE mulai dari tingkat institusi. Persepsi mereka terhadap metode pembelajaran IPE dapat menjadi modal utama pengembangan IPE.

Selain mahasiswa, pendidik yang dalam hal ini adalah dosen juga perlu mengenal sejauh mana peran dan fungsi IPE dalam kurikulum institusi yang nantinya akan menjadi bekal mahasiswa dalam berkolaborasi di dunia kerja yang sesungguhnya dengan profesi kesehatan lainnya. Dosen dituntut untuk dapat memfasilitasi pembelajaran IPE kepada mahasiswa, selain itu dosen juga diharapkan untuk menanamkan kepada mahasiswa tentang pentingnya memahami kompetensi profesi kesehatan lain, menghargai peran profesi kesehatan lain, memiliki pengalaman kolaborasi dan mampu menjadi role mode (Mariyono dan Claramita, 2014).

Diperlukan adanya kurikulum yang dapat melatih mahasiswa tenaga kesehatan untuk berkolaborasi sejak masa akademik agar mereka terbiasa berkolaborasi dengan profesi lain bahkan sampai ketika mereka berada didunia kerja (Reeves, et al., 2011).

\section{KESIMPULAN}

1. Persepsi mahasiswa dalam pembelajaran IPE di prodi D-III Akupunktur Jurusan Akupunktur Politeknik Kesehatan Kemenkes Surakarta sebanyak 36 orang $(92,31 \%)$ memberikan persepsi baik dan sebanyak 3 orang $(7,69 \%)$ memberikan persepsi sedang.

2. Persepsi dosen dalam pembelajaran IPE di prodi D-III Akupunktur Jurusan Akupunktur Politeknik Kesehatan Kemenkes Surakarta sebanyak 12 orang $(85,7 \%)$ memberikan persepsi baik dan 2 orang (14,3\%) memberikan persepsi sedang.

\section{SARAN}

1. Untuk penelitian berikutnya diharapkan dapat melibatkan jurusan-jurusan lainnya yang ada di Politeknik Kesehatan Kemenkes Surakarta supaya hasil penilaian terhaap persepsi dalam pembelajaran IPE lebih bervariasi.

2. Pada penelitian selanjutnya diharapkan dapat membahas lebih dalam mengenai faktorfaktor yang dapat mempengaruhi persepsi baik dari mahasiswa maupun dosen, agar dapat memperbaiki cara pengajaran atau pembelajaran IPE pada kurikulum selanjutnya.

\section{DAFTAR PUSTAKA}

Fuadah, D. Z. 2014. Kesiapan Mahasiswa Untuk Belajar Kerjasama Inteprofesi Dalam Perawatan Antenatal. Tesis. Program Studi Magister Keperawatan. Universitas Gadjah Mada, Yogyakarta.

Fauziyah, F. A. 2010. Analisis Gambaran Persepsi dan Kesiapan Mahasiswa Profesi FK UGM terhadap Interprofessional Education di Tatanan Pendidikan Klinik. Skripsi. Program Studi 
IImu Keperawatan Fakultas Kedokteran Universitas Gajah Mada, Yogyakarta.

World Health Organization. 1988. Working Together for Health. World Health Organization, Geneva.

Lee, R. 2009. Interprofessional Education: Principles and Application Pharmacotherapy, 29 (3); 145e-164e.

Sarwono, S. W. 1996. Pengantar Umum Psikologi. Rajawali Pers, Jakarta.

Ulung, D. K. 2014. Persepsi Mahasiswa Fakultas Kedokteran dan IImu Kesehatan UIN Syarif Hidayatullah Jakarta Terhadap Interprofessional Education. Skripsi. Program Studi IImu Keperawatan. Universitas Islam Negeri Syarif Hidayatullah, Jakarta.
Mariyono, S. dan M. Claramita. 2014. Buku Acuan Umum-CFHC IPE.

Reeves, S., Lewin, S., Espin, S., Zwarenstein, M., dan Ed, H. B. $2011 . \quad$ Interprofessional Teamwork for Health and Social Care. , pp.32-33.

Finch, J. 2000. Interprofessional education and teamworking. a view from the education provider, 321(7269), p. 1138-1140.

World Health Organization. 2010. Framework for action on interprofessional education and collaborative practice. World Health Organization, Geneva.

${ }^{1}$ Dosen Jurusan Akupunktur Poltekkes Kemenkes Surakarta ${ }^{2}$ Dosen Akper Insan Husada Surakarta 